\title{
Burnout Factors in Private Health and Fitness Centers' Sector: A Case Study in Greece
}

\author{
Yannis Georgiou ${ }^{1}$, Aggeliki Fotiou ${ }^{2}$ \\ ${ }^{1}$ National and Kapodistrian University of Athens, the School of Physical Education and Sport Science, Athens, Greece, ${ }^{2} \mathrm{Hellenic}$ Open University, \\ School of Social Sciences, Faculty of Business Administration, Patras, Greece
}

\begin{abstract}
The aim of the research was to investigate conceiving levels of Burnout, in employees in private fitness and health centers of the prefecture of Attica, Greece in relation with demographic factors such as gender, age, familial situation and level of education. Participants $(n=185)$ answered in a demographic questionnaire and the MBI-GS (Maslach Burnout Inventory-General Survey) questionnaire in 16 questions, in reference to the three factors of the Burnout Syndrome, Emotional Exhaustion, Depersonalization, and Personal Accomplishments. The analysis of variation (ANOVA), did not show any significant statistical differences between the independent variables and the three factors of the dependent one. However, the agreement of results of the present research, with similar research in the public sector, as well as the differences that are presented concerning other occupational groups, tend in the affair of the relation of the content of work and environmental labor factors that are perhaps connected with the existence of Burnout.
\end{abstract}

Key words: Exhaustion, Depersonalization, Cynicism, Stress

\section{Introduction}

Shirom (2005) agreed that a syndrome refers to a set of signs and symptoms that characterize a particular malfunction. Burnout Syndrome (BS) is characterized by Emotional Exhaustion (EE), depersonalization (D)/cynicism and reduced Professional Achievements (PA) and is derived from chronic exposure to stressors (Maslach, Schaufeli \& Leiter, 2001). Chronic exposure to occupational factors, manifests BS and leads mathematically to the bad physical, the psychological and mental health state of the employee, and as a result to several disorders and health problems (Schaufeli \& Bakker, 2004).

Although burnout was at first addressed to the human service professions, it can also be found in other types of occupations. Recently, the concept of burnout has also begun to appear frequently in the sport, health, and fitness industry services worldwide and recently in Greece (Kelley, Eklund, Ritter, \& Taylor, 1999; Koustelios, 2010; Koustelios, 2001; Koustelios \& Tsigilis, 2005; Koustelios, Zounatzi, \& Karabatzaki, 2012; Martin, Kelley, \& Dias, 1999; Tsigilis, Zournatzi, \& Koustelios, 2011). Some similar researches have been contacted also in Greece, in different occupational environments, also in the sports services area, but never before in the private sector of the health and fitness services centers. Several occupational as far as individual factors are responsible for the evolution of BS. Many studies in the past investigate some of the abovementioned factors intensively among them gender, age, marital status, type of employment and level of education.

Gender is most commonly the first factor concerning the interest of the researchers of the field. There are several results referred to participants' differences concerning gender which can also be a predictive factor of EE and D (Tang \& Lau, 1996). Females show to be more vulnerable to EE than their males counterparts (Giacobbi Jr., 2009), while males seem to be more vulnerable to $\mathrm{D}$ than females do (Twellaar, Winants, \& Houkes, 2008). Other results present that females employees may evolve higher levels of BS than males do (Bakker, Demerouti, \& Schaufeli, 2002), and this is a factor which predicts work absence for females but not for males employees (Duijts, Kant, Landeweerd, \& Swaen, 2006). In Greece, Antoniou (1999) agreed that female doctors showed higher levels of EE

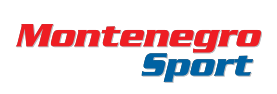

\section{Correspondence:}

\section{Y. Georgiou}

National \& Kapodistrian University of Athens, School of Physical Education and Sport Science 33, Terpsichoris str., Agios Dimitrios, 17341, Athens, Greece

E-mail: georgiougiannis72@gmail.com 
but on the contrary in the public sector of health and fitness centers employees, gender seems to have no differences considering both BS evolvement and prediction (Koustelios, 2001).

The Burnout Syndrome shows different correlations with different age groups, with younger employees having higher EE and $\mathrm{D}$ and lower PA rates than older employees have (Maslach \& Jackson, 1981). Age variable also is a predictive factor of BS, as younger employees showed high levels of BS while the older ones showed lower, with the high correlation between age and time of service, indicating that job experience acts as a deterrent to the emergence of BS (Randall, 2007; Rich \& Rich, 1987), and lack of experience partly explains the negative correlation between age and BS (Bakker, Demerouti, \& Schaufeli, 2002), with particular emphasis on the sub-scale of EE (Tuuli \& Karisalmi, 1999) as younger employees experience higher work pressure from their older colleagues (Tomic, Tomic, \& Evers, 2004). Concerning female participants in different age groups, (18-33, 34-49, 50-65), younger age groups had a negative correlation while for the older age groups had a positive correlation with BS, while male participants, showed a positive correlation in the middle age groups and no correlation for the other two age groups (Ahola, Honkonen, Virtanen, Aromaa, \& Lönnqvist, 2008). In Greece, Antoniou (1999) in his results showed that younger ages' BS evolution is higher than older ages' are but Koustelios (2001) presented results showing that there was no correlation between the two variables concerning the employees in public gyms.

Marital status seems to affect the occurrence of BS since the employee has also to cope with another role such as that of the spouse or parent. In this sense, it is obvious why the emergence of high levels of labor-to-family conflict also anticipates increased levels of BS (Allen, Herst, Bruck, \& Sutton, 2000). Data presented indicate that the marital status factor is significantly correlated with the sub-scale of EE. On the other hand, unmarried and divorced showed higher rates, both in the frequency and severity of EE than married did (Maslach \& Jackson, 1981). In Greece Antoniou (1999) presents that unmarried evolves higher level of BS than married participants did.

Type of employment, as a characteristic of the work environment which contributes to the BS evolvement, can be an extra potential stressor. Part time employees experience job insecurity, stigmatization, and social isolation because of their colleagues who believe that they have low skills levels. As a result, part-time and hourly wage-paid employees they do not get the appropriate support on behalf of their colleagues and/or their supervisors (Crozier \& Davidson, 2009). This will lead the non-full time employees to experience negative emotions and as a chain reaction to symptomatic behavior such as depression (Larson, 1993).

Concerning the factor of the level of education, graduates show higher levels of EE and lower levels of D than the less educated. In the sub-scale of PA, it was shown that the higher the employee's educational level is, the higher their performance (Maslach \& Jackson, 1981). In Greece Antoniou (1999) agreed that medical occupation employees with lower educational level safer more BS symptoms that their higher educated colleagues.

In conclusion, gender, age, marital status, type of employment and education levels, as research factors in correlation with the BS, give contradictive results, while there is not of wide scientific interest in the private sport, health, and fitness sector. Especially in Greece the literature is not as expanded as it should be. For this reason this research is constructed for.

Methods

The survey involved 185 employees in private gyms in the city of Athens, Greece, of which 93 (50.3\%) males and 92 (49.7\%) females. The sample was selected by gradual and random sampling. Selected method to measure burnout was that of self-completed questionnaires. Researchers informed all participants for the voluntary character of their participation and the confidentiality of the individual responses.

Two questionnaires distributed. The first was the demographic, which contained general questions concerning gender, age, marital status, type of employment, and level of education of employees. The second was the Maslach Burnout Inventory-General Survey Scale (MBI-GS) (Maslach, Jackson, \& Leiter, 1996)

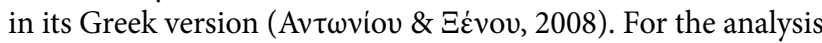
of the data, descriptive statistics with Mean Values and Standard Deviations as far as Analysis of Variation (ANOVA) for independent samples (sex, age, marital status, employment, work position and level of education) took place.

\section{Results}

Gender. ANOVA's results showed no statistically significant differences between males and females participants concerning the factors of the syndrome. Mean Values and Standard Deviations for Emotional Exhaustion, Depersonalization and Personal Achievements are shown in Table 1.

Table 1. Mean Values (M.V.) and Standard Deviations (S.D.) of MBI-GS factors and Gender $(n=185)$

\begin{tabular}{lcccc}
\hline \multirow{2}{*}{ Burnout Sub-scales } & \multicolumn{3}{c}{ Gender } \\
\cline { 2 - 5 } & \multicolumn{2}{c}{$\begin{array}{c}\text { Males } \\
(\mathbf{n = 9 3 )}\end{array}$} & \multicolumn{2}{c}{$\begin{array}{c}\text { Females } \\
(\mathbf{n = 9 2 )}\end{array}$} \\
\cline { 2 - 5 } & M.V. & S.D. & M.V. & S.D. \\
\hline 1. Emotional Exhaustion & 2.82 & 1.35 & 2.86 & 1.33 \\
2. Depersonalization & 2.00 & 1.22 & 2.15 & 1.31 \\
3. Personal Achievements & 5.26 & 0.80 & 5.18 & 0.89 \\
\hline
\end{tabular}

Emotional Exhaustion $(\mathrm{F} 1.178=.028, \mathrm{p}=.868, \mathrm{MSE}=1.798)$, the Depersonalization $(\mathrm{F} 1,180=.347, \mathrm{p}=.556$, MSE $=.716)$, and the Personal Achievements $(\mathrm{F} 1,178=.645, \mathrm{p}=.423, \mathrm{MSE}=1,600)$.

Age. The Mean Values of the three factors of the MBI-GS scale were compared, based on two age groups, 18-32 and 33-47 of the employees. The age group of $48+$ consisted of only 6 people and it was excluded from the analysis. ANOVA's results did not show any statistically significant differences in all the three factors of the syndrome concerning the age groups. 
Table 2. Mean Values (M.V.) and Standard Deviations (S.D.) of MBI-GS factors and Age ( $n=183$ )

\begin{tabular}{|c|c|c|c|c|c|c|c|c|}
\hline \multirow{4}{*}{ Burnout Sub-scales } & \multicolumn{8}{|c|}{ Age groups } \\
\hline & \multicolumn{4}{|c|}{ Males } & \multicolumn{4}{|c|}{ Females } \\
\hline & \multicolumn{2}{|c|}{$\begin{array}{c}18-32 \\
(n=47)\end{array}$} & \multicolumn{2}{|c|}{$\begin{array}{l}33-47 \\
(n=42)\end{array}$} & \multicolumn{2}{|c|}{$\begin{array}{c}18-32 \\
(n=65)\end{array}$} & \multicolumn{2}{|c|}{$\begin{array}{c}33-47 \\
(n=23)\end{array}$} \\
\hline & M.V. & S.D. & M.V. & S.D. & M.V. & S.D. & M.V. & S.D. \\
\hline 1. Emotional Exhaustion & 2.91 & 1.29 & 7.73 & 1.38 & 2.84 & 1.37 & 2.88 & 1.29 \\
\hline 2. Depersonalization & 2.13 & 1.29 & 1.97 & 1.18 & 1.94 & 1.24 & 2.65 & 1.36 \\
\hline 3. Personal Achievements & 5.09 & 0.94 & 5.42 & 0.59 & 5.14 & 0.96 & 5.28 & 0.65 \\
\hline
\end{tabular}

Emotional Exhaustion, Personal Achievement and Depersonalization, respectively, relatively to age $(\mathrm{F} 1,162=.103$, $\mathrm{p}=.749, \mathrm{MSE}=1.802),(\mathrm{F} 1,162=2.721, \mathrm{p}=.101, \mathrm{MSE}=1.948)$, $(\mathrm{F} 1.162=1.737, \mathrm{p}=.189, \mathrm{MSE}=1.574)$.

Marital Status. ANOVA's results show no statistically significant differences between different marital status employees concerning the subscales of BS. The mean values and standard deviations of emotional exhaustion, depersonalization and personal achievement according to marital status are shown in Table 3.

Table 3. Mean Values (M.V.) and Standard Deviations (S.D.) of MBI-GS factors and Family Status $(\mathrm{n}=178)$

\begin{tabular}{|c|c|c|c|c|}
\hline \multirow{3}{*}{ Burnout Sub-scales } & \multicolumn{4}{|c|}{ Marital Status } \\
\hline & \multicolumn{2}{|c|}{$\begin{array}{l}\text { Married } \\
(n=44)\end{array}$} & \multicolumn{2}{|c|}{$\begin{array}{c}\text { Unmarried } \\
(n=134)\end{array}$} \\
\hline & M.V. & S.D. & M.V. & S.D. \\
\hline 1. Emotional Exhaustion & 2.76 & 1.49 & 2.87 & 1.29 \\
\hline 2. Depersonalization & 2.10 & 1.38 & 2.06 & 1.23 \\
\hline 3. Personal Achievements & 5.29 & 0.68 & 5.19 & 0.91 \\
\hline
\end{tabular}

Results for Emotional Exhaustion, Depersonalization and Personal Achievement respectively $(\mathrm{F} 1,172=.243, \mathrm{p}=.623$, $\mathrm{MSE}=1.798, \mathrm{~F} 1,173=.446, \mathrm{p}=.505, \mathrm{MSE}=.733, \mathrm{~F} 1,171=.030$, $\mathrm{p}=.863, \mathrm{MSE}=1.608)$.

Type of employment. ANOVA's results show no statistically significant differences in the type of employment (full time, part time and hourly wage paid) concerning the subscales of BS. Mean Values and Standard Deviations for Emotional Exhaustion, Depersonalization and Personal Achievements by type of employment are shown in Table 4 .

Table 4. Mean Values (M.V.) and Standard Deviations (S.D.) of MBI-GS factors and Type of Employment $(n=181)$

\begin{tabular}{lcccccc}
\hline \multirow{2}{*}{ Burnout Sub-scales } & \multicolumn{5}{c}{ Type of Employment } \\
\cline { 2 - 7 } & \multicolumn{2}{c}{ Full time $(\mathbf{n = 8 7})$} & \multicolumn{2}{c}{ Part Time (n=55) } & \multicolumn{2}{c}{ Hourly Wage (n=39) } \\
\cline { 2 - 7 } & M.V. & S.D. & M.V. & S.D. & M.V. & S.D. \\
\hline 1. Emotional Exhaustion & 2.77 & 1.32 & 2.89 & 1.47 & 2.88 & 1.28 \\
2. Depersonalization & 2.03 & 1.29 & 2.05 & 1.43 & 2.19 & 0.95 \\
3. Personal Achievements & 5.10 & 0.81 & 5.36 & 0.70 & 5.16 & 1.10 \\
\hline
\end{tabular}

Emotional Exhaustion $(\mathrm{F} 2,173=.160, \mathrm{p}=.852, \mathrm{MSE}=1,838)$, Depersonalization $(\mathrm{F} 2,175=1,301, \mathrm{p}=.275$, MSE $=.720)$ and Personal Achievements $(\mathrm{F} 2,174=.212, \mathrm{p}=.809, \mathrm{MSE}=1.615)$.

Education level. ANOVA's results show no statistically significant differences between education level and BS' subscales. Mean Values and Standard Deviations for Emotional Exhaustion, Depersonalization and Personal Achievements according to the level of Education are shown in Table 5.

Table 5. Mean Values (M.V.) and Standard Deviations (S.D.) of MBI-GS factors and Education's level $(n=177)$

\begin{tabular}{llccc}
\hline & \multicolumn{4}{c}{ Education Level } \\
\cline { 2 - 5 } Burnout Sub-scales & \multicolumn{2}{c}{$\begin{array}{c}\text { Up to secondary } \\
(\mathbf{n = 3 9 )}\end{array}$} & $\begin{array}{c}\text { University or higher } \\
(\mathbf{n = 1 3 8 )}\end{array}$ \\
\cline { 2 - 5 } & M.V. & S.D. & M.V. & S.D. \\
\hline 1. Emotional Exhaustion & 2.54 & 1.27 & 2.89 & 1.33 \\
2. Depersonalization & 2.13 & 1.19 & 2.04 & 1.30 \\
3. Personal Achievements & 5.12 & 0.87 & 5.23 & 0.85 \\
\hline
\end{tabular}

Emotional exhaustion $(\mathrm{F} 1,170=2.106, \mathrm{p}=.149, \mathrm{MSE}=1.734), \quad$ Personal Achievements $(\mathrm{F} 1,171=.466, \mathrm{p}=.496, \mathrm{MSE}=1.599)$. Depersonalization $(\mathrm{F} 1.172=143, \mathrm{p}=.706, \mathrm{MSE}=1.599)$ and 


\section{Discussion}

The aim of the present study was to investigate the BS evolution within the context of private health and fitness centers in the city of Athens, Greece. The independent variables selected according to the literature referred to gender, age, marital status, type of employment and level of education, while the dependent variables consisted of the three sub-scales of BS, Emotional Exhaustion, Depersonalization, and reduced Personal Achievements.

Concerning the variable of gender, the results are contradictive in the sense that, although many previous results presenting either negative or positive correlation with BS in the past (Tang \& Lau, 1996; Giacobbi, 2009; Twellaar et al., 2008; Bakker, Demerouti, \& Schaufeli, 2002; Duijts et al., 2006; Antoniou, 1999), our results are in line only with Koustelios (2001), who agreed that in the same occupational sector, but in public health and fitness centers, there is no correlation between gender and BS.

Similarly, while there is extensive scientific results' literature with reference to the correlation of age and BS, our results show no significance at all. More specific, in our literature review, we recorded significant correlations between different age groups and BS sub-scales and we saw age factor to be predictive of BS (Ahola et al., 2008; Antoniou, 1999; Bakker et al., 2002; Maslach \& Jackson, 1981; Rich \& Rich, 1987; Tomic, Tomic, \& Evers, 2004; Tuuli \& Karisalmi, 1999). Though this, our results show again no correlation between age groups and BS.

Literature review presented contradictive results concerning a conflict between the different roles someone is supposed to play in daily life - employee, parent, partner etc.- as a factor of BS evolvement (Allen, Herst, Bruck, \& Sutton, 2000), while from the other side, partnership can provide social support in the context of the family and relief the employee from negative occupational effects (Antoniou, 1999; Maslach \& Jackson, 1981). In our results there was no significance between the marital status of the participants and BS evolution.

A long discussion has been done, for the negative effects of part-time and hourly wage payment towards full-time employment status, with the first two types of employment to be mentioned as causal factors of insecurity and poor social support in the occupational environment, which lead to employee's poor health and symptomatic behavior (Crozier \& Davidson, 2009; Larson,1993). The results of the present research shown no significance between the three types of employment and BS.

Last but not least, and although there are scientific results' evidences for the correlation between the level of education and BS and its sub-scales as much internationally (Maslach \& Jackson, 1981) as in Greece Antoniou (1999), the results presented above so no statistical significance between the education factor and BS.

In total all the five factors investigated gave no statistically significant differences. These results are, contradictive to the majority and only partly matching with the minority, of previous research results. Investigating five common factors, without any statistically significance, it may pinpoints that there are other factors that they may correlate with the absence of BS in the private sport services sector, which are in our interest of a future research. The majority of the par- ticipants were Physical Education teachers, which explains the high rate of university education level in the sample. The type of employment may not cause an effect because of a second job existing or because this is the second job. Differences concerning the age groups may not appear because the older age group consisted of only six persons. This is maybe because of the nature of the job, as a trainer must be physically fit and endurable to complete his duties in a proper way, something that also matches with the younger ages.

Although there are some explanations can be given, these are based upon assumptions and not proofs. It would be wiser if in a future research, the factors investigated would be organizational factors like organizational environment, organizational culture and job content of health and fitness centers and their employees. This will help us to understand the wider concept of sports services industry and the reasons why there are so many contradictive results with other researches concerning the evolvement of BS.

Finally, it has to be mentioned that these results cannot be generalized due to the nature of the sample which is taken only from the city of Athens and not from representative regions all over Greece. Despite the abovementioned restriction, this research presents that socio-demographic factors do not evolve BS in the concept of the private sport, health, and fitness sector. In parallel with results of the same type of researches in the public sector which show the same direction, it can be assumed, that other organizational factors may contribute in the opposite direction of BS evolvement. Future researches should move towards the path of the organizational environment of the sport, health, and fitness services and make clear which factors affect the moderation of BS evolvement positively. If these factors can be identified and screened, they can also be used as an antidote against BS evolvement, not only in the sport services spectrum but in every organizational environment.

\section{Acknowledgements}

There are no acknowledgements.

\section{Conflict of Interest}

The authors declare that there are no conflicts of interest.

Received: 29 March 2019| Accepted: 26 April 2019| Published: 4 July 2019

\section{References}

Ahola, K., Honkonen, T., Virtanen, M., Aromaa, A., \& Lönnqvist, J. (2008). Burnout in Relation to Age in the Adult Working Population. Journal of Occupational Health, 50, 362-365.

Allen, T.D., Herst, D.E.L., Bruck, C.S., \& Sutton, M. (2000). Consequences Associated with Work - to - Family Conflict: A Review and Agenda for Future Research. Journal of Occupational Health Psychology, 5(2), 278-308.

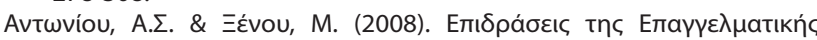

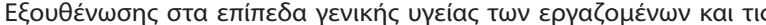

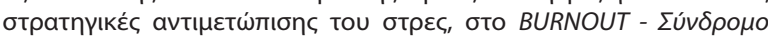

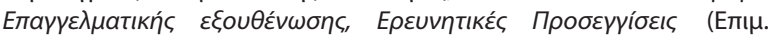

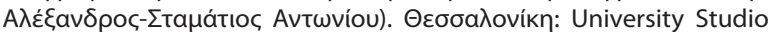
Press [Greek].

Antoniou, A.S. (1999). Personal traits and professional burnout in health professionals. Archives of Hellenic Medicine, 16(1), 20-28.

Bakker, A.B., Demerouti, E., \& Schaufeli, W.B. (2002). Validation of the Maslach Burnout Inventory - General Survey: An Internet study. Anxiety, Stress, and Coping, 15(3), 245-260.

Crozier, S.E. \& Davidson, M.J. (2009). The challenges facing the temporary workforce: an examination of stressors, wellbeing outcomes and gender differences. In Antoniou, C. Cooper, G. Chrousos, C. Spielberger, \& M. Eysenck. Handbook of Managerial Behaviour and Occupational Health (206-217). Northampton, USA: Edward Elgar. 
Duijts, S.F.A., Kant, I.J., Landeweerd, J.A., \& Swaen, G.M.H. (2006). Prediction of sickness absence: development of a screening instrument. Occupational and Environmental Medicine, 63(8), 564-569.

Giacobbi Jr., P.R. (2009). Low Burnout and High Engagement Levels in Athletic Trainers: Results of a Nationwide Random Sample. Journal of Athletic Training, 44(4), 370-377.

Kelley, B., Eklund, R., Ritter, C., \& Taylor, M. (1999). Stress and burnout among collegiate tennis coaches. Journal of Sport and Exercise Psychology, 21(2), 113-130.

Koustelios, A. (2001). Burnout among Greek sport centers employees. Sport Management Review, 4(2), 151-163.

Koustelios, A. (2010). Burnout among football coaches in Greece. Biology of Exercise, 6(1), 47-54.

Koustelios, A. \& Tsiggilis, N. (2005). Relationship between burnout and job satisfaction among physical education teachers: A multivariate approach. European Physical Education Review, 11(2), 189-203.

Koustelios, A., Zounatzi, E., \& Karabatzaki, D. (2012). Burnout and autonomy among Physical Education teachers in Greece. International Journal of Physical Education, 2.

Larson, S.J. (1993). The measurement of social well-being. Social Indicators Research, 28(3), 285-296.

Martin, J., Kelley, B., \& Dias, C. (1999). Stress and burnout in female high school athletic directors. Women in Sport and Physical Activity Journal, 8(1), 101-116.

Maslach, C. \& Jackson, S.E. (1981). The measurement of experienced burnout. Journal of Occupational Behaviour, 2, 99-113.

Maslach, C., Schaufeli, W.B., \& Leiter, M.P. (2001). Job burnout. Annual Review of Psychology, 52, 397-422.
Randall, K.J. (2007). Examining the relationship between burnout and age among Anglican clergy in England and Wales. Mental Health, Religion \& Culture, 10(1), 39-46.

Rich, V.L. \& Rich, A.R. (1987). Personality Hardiness and Burnout in Female Staff Nurses. Journal of Nursing Scholarship, 19(2), 62-66.

Schaufeli, W.B. \& Bakker, A.B. (2004). Job demands, job resources, and their relationship with burnout and engagement: a multi-sample study. Journal of Organizational Behavior, 25(3), 293-315.

Shirom, A. (2005). Reflections on the study of burnout. Work \& Stress, 19(3), $263-270$.

Tang, C.S-K., \& Lau, B.H-B. (1996). Gender role stress and burnout in Chinese human service professionals in Hong Kong. Anxiety, Stress \& Coping, 9(3), 217-227.

Tomic, W., Tomic, D.M., \& Evers, W.J.G. (2004). A question of burnout among reformed church ministers in The Netherlands. Mental Health, Religion \& Culture, 7(3), 225- 247

Tsigilis, N., Zachopoulou, E., \& Grammatikopoulos, V. (2006). Job satisfaction and burnout among Greek early educators: A comparison between public and private sector employees. Educational Research and Review, 1(8), 256-261.

Tuuli, P., \& Karisalmi, S. (1999). Impact of Working Life Quality on Burnout. Experimental Aging Research, 25(4), 441-449. doi:10.1080/036107399243922

Twellaar, M., Winants, Y., \& Houkes, I. (2008). How healthy are Dutch general practitioners? Self-reported (mental) health among Dutch general practitioners. European Journal of General Practice, 14(4), 9. 